This item was submitted to Loughborough's Research Repository by the author.

Items in Figshare are protected by copyright, with all rights reserved, unless otherwise indicated.

\title{
Exercise attitudes and behaviours among retired female collegiate athletes
}

PLEASE CITE THE PUBLISHED VERSION

http://dx.doi.org/10.1016/j.psychsport.2017.01.001

\section{PUBLISHER}

(c) Elsevier

\section{VERSION}

AM (Accepted Manuscript)

\section{PUBLISHER STATEMENT}

This work is made available according to the conditions of the Creative Commons Attribution-NonCommercialNoDerivatives 4.0 International (CC BY-NC-ND 4.0) licence. Full details of this licence are available at: https://creativecommons.org/licenses/by-nc-nd/4.0/

\section{LICENCE}

CC BY-NC-ND 4.0

\section{REPOSITORY RECORD}

Plateau, Carolyn, Trent A. Petrie, and Anthony Papathomas. 2019. "Exercise Attitudes and Behaviours Among Retired Female Collegiate Athletes". figshare. https://hdl.handle.net/2134/23876. 
$8 \quad{ }^{a}$ National Centre for Sport and Exercise Medicine, Loughborough University, Loughborough,

$9 \quad$ LE11 3TU, UK. C.R.Plateau@lboro.ac.uk; A.Papathomas@lboro.ac.uk.

$10{ }^{\mathrm{b}}$ Department of Psychology, University of North Texas, Denton, TX 76203, United States.

11 Trent.Petrie@unt.edu

12 *Corresponding author: Carolyn Plateau, National Centre for Sport and Exercise Medicine,

13 Loughborough University, Loughborough, LE11 3TU, UK. Phone: (+44) 1509228487.

14 Email: $\underline{\text { C.R.Plateau@lboro.ac.uk }}$ 


\section{Abstract}

5 Objectives: The present study explored exercise attitudes and behaviours among retired 6 female collegiate athletes.

7 Design: A survey design incorporating both closed and open-ended questions was adopted.

8 Method: A total of 218 former NCAA Division I female athletes ( $n=144$ gymnastics; $n=74$

9 swimming/diving) provided details on their current exercise behaviours and their thoughts 10 regarding exercise since retiring from collegiate sport.

11 Results: No relations were found between years since retirement and athletes' current 12 exercise frequency, types of exercise activities, and reasons for exercising. Despite reporting 13 activity levels consistent with recommendations (5 days/week, 1 hour per session), retired 14 athletes remained dissatisfied with their activity levels and struggled to integrate exercise 15 alongside occupational, academic and social demands.

16 Conclusions: Athletes may require support in adapting to an independent and less intense 17 exercise regime on retirement. Future research may look to explore exercise attitudes and behaviours among retired athletes from a longitudinal perspective.

19 Keywords: sport; career transition; health; physical activity 


\section{Introduction}

Retirement from sport can be a difficult period for athletes, and significant reductions in self-esteem, physical self-worth, and perceived physical attractiveness are common (Stephan et al., 2003a, b). The transition is often characterised by an initial period of crisis and uncertainty, followed by the construction of a new identity and improved psychological well-being (Kerr \& Dacyshyn, 2000). Although clear time frames for this transition have yet to be established, existing evidence suggests that adjusting to life beyond sport becomes easier as time since retirement lengthens (Douglas \& Carless, 2009; Lally, 2007). Other factors such as not solely identifying as an athlete, retiring voluntarily and having a supportive social network can also ease the transition (Park et al., 2013).

Athletes also experience challenging physical changes on retirement from sport. Notably, retirement has been linked to weight gain and reduced muscle mass (Marquet et al., 2013; Stirling et al., 2012), which can be ascribed to reductions in physical activity and changes in food intake (Weiler et al., 2015). Some retired athletes report engaging in compensatory exercise behaviours, such as rigid or driven exercise, to cope with these bodily changes (Lavallee \& Robinson, 2007; Stirling et al., 2012). In contrast, other athletes relate more positively to exercise, citing the benefits of recreational activity to reduce their decline in fitness and to help maintain a routine after the cessation of formal sport training (Clowes et al., 2015; Stambulova et al., 2007). During their competitive careers, collegiate athletes engage in highly structured and externally regulated training with their teammates, with performance improvement a primary goal (Theberge, 2007). On retirement, athletes must make the transition towards exercising independently, which includes making decisions about the type and quantity of exercise performed, as well as finding new motivations for exercise. Maintaining an active lifestyle beyond the end of a competitive sport career can be beneficial to physical and psychological health (Witkowski \& Spangenburg, 2008). At 
1 present there is conflicting evidence around the exercise attitudes and behaviours of former

2 athletes and a limited understanding of how athletes make sense of exercise into retirement.

3 Questions remain about what happens to activity levels among athletes once they are no

4 longer involved in competitive sport. What physical activities do athletes engage in, and for

5 what reasons are they exercising or not? Further, do such exercise attitudes and behaviours

6 vary based on years since retirement? In this brief report we aimed to (a) determine if there

7 was a relation between years since retirement and athletes' current exercise frequency, types

8 of exercise activities, and reasons for exercising, and (b) to explore athletes' perspectives

$9 \quad$ towards exercise since retiring from collegiate sport.

\section{Method}

\section{Participants}

Participants $(n=325)$, who represented all regions of the United States, were invited to participate in a follow up study exploring the well-being of retired female collegiate athletes, six years after the baseline study (XXX et al.). A total of 218 athletes took part (response rate $=67.1 \%)$. Participants had previously competed in gymnastics $(n=144)$ or swimming/diving $(n=74)$ at the NCAA Division I level. Athletes had been retired from collegiate sport for 2-3 years $(n=53), 4$ years $(n=52), 5$ years $(n=61)$, and 6 years $(n=51)$. Athletes retired from their sport due to completing their NCAA eligibility ( $n=176 ; 76.6 \%$ ), injury ( $n=32 ; 14.7 \%$ ), no longer wanting to train/compete anymore $(n=8 ; 3.7 \%)$, removal from team by coaching staff ( $n=2 ; 0.9 \%)$, and “other” ( $n=9 ; 4.2 \%)$. Mean age and BMI were 25.72 years $(S D=$ 1.19) and $22.31 \mathrm{~kg} / \mathrm{m}^{2}(S D=2.72)$, respectively. The majority were White/ NonHispanic $(n=$ 192; 88.1\%) and married or in a romantic relationship ( $n=165 ; 75.8 \%)$. Ethical approval was granted by the University of XXX Institutional Review Board. Athletes received a \$25 giftcard for participation; responses were only identified by a unique code. Data were collected across the entire calendar year of 2015. 


\section{Procedure}

Through a secure website, athletes provided demographic information (e.g., age, weight) and reported on their current exercise activities. First, over the past month, participants reported the average number of days per week they exercised and the length (in minutes) of each session. Second, from a list of seven categories (i.e., aerobic/endurance,

6 strength/resistance, exercise classes such as Zumba, core strength activities such as

7 yoga/pilates, playing team sports, cross-fit, and “other”), participants indicated the percent of exercise time spent in each activity each week; percentages had to equal 100 across the categories. Third, participants rated each of 10 reasons for exercise (e.g., socialize, improve physical health, improve strength/muscularity) on a scale from 1 (not at all important) to 7 (extremely important).

Participants also indicated whether they perceived their physical activity levels to have changed since retiring from sport. Positive responders completed two additional, open-ended questions: (a) "Please describe the changes that have occurred in your physical activity levels AND how you have felt about these changes;" and (b) "Please describe how you have coped with these changes in your physical activity levels.” Open-ended surveys are valuable for ascertaining qualitative data from large samples, and have previously been used for investigating athletes’ attitudes and experiences (Beals, 2003; Kerr et al., 2006). Participants could write as much as they wanted to and there was no time restriction.

\section{Data analysis}

To address the first aim, we used the number of years since retirement as the independent variable (four levels, i.e., 2-3 years, 4 years, 5 years, and 6 years) and the athletes' overall days per week spent exercising, minutes per exercise session, percentage of time spent in each exercise activity, and reasons for exercising as the dependent variables. Specifically, we used separate ANOVAs to examine the relation of time in retirement to days 
1 per week exercising and then to minutes spent in each exercise session. We used separate

2 MANOVAs to test how time since retirement related to percentage of time spent in each of

3 the seven specified exercises and to importance the athletes gave to the 10 different reasons

4 for exercising. Alpha was set at .05 for each analysis. Means, SDs, and frequencies (\%) were

5 used to describe the data.

6 Our inductive analysis of responses to the open-ended questions followed Braun,

7 Clarke and Weate's (2016) rigorous stages of thematic analysis. First, multiple readings of

8 the data facilitated familiarisation; next, the data were systematically coded and grouped into

9 potential themes. In accordance with suggestions from Braun, Clarke \& Weate (2016),

10 coding was driven by the salience of the response as opposed to the length or frequency of

11 responses. In line with our descriptive approach, coding was predominately explicit focussing on overt meaning - rather than implicit. Labels for the themes were then generated, and representative data extracts identified. Themes were given broad names to allow for nuance and variability of experience. Discussions took place within the research team throughout the analysis process; not to promote consensus but rather to ensure diligent consideration of alternative interpretations (see Yardley, 2014). This flexible analytical approach (Braun et al., 2016) comes without allegiance to a particular theoretical lens and without stipulations regarding how data should be collected. As such, it can be useful for making sense of data when the aim is to be primarily descriptive rather than interpretive. This said, the descriptive approach here does not beget a commitment to a realist thematic analysis; we are of the position that participants' perspectives are not indicative of a fixed, objective Truth but rather are mind-dependent constructions. Our analytical claims fall in line with these relativistic assumptions by emphasising what was “reported” and “described” rather than what was “found” or “discovered” (see Smith \& Deemer, 2000).

\section{Results}


The ANOVAs and MANOVAs across the four dependent variables were nonsignificant in relation to the athletes' years since retirement (all p's $>0.53$ ), thus we present the athletes' exercise activities and reasons based on the full sample. The retired athletes reported exercising almost five days a week $(M=4.72, S D=1.64)$ and for approximately one hour per session $(M=55.45$ minutes, $S D=27.80)$. The percentage of time spent in each of the seven exercise activities differed significantly, Wilks’ Lambda $=.234, F(6,211)=115.264, p$ $<.0001$, partial $\eta^{2}=0.77$. The athletes spent most of their exercise time engaging in cardiorespiratory/ endurance activities (e.g., running, swimming, biking) and strength or resistance training (e.g., free weights, kettle bells). Playing sports was the least frequent activity (Table 1).

The reasons that the athletes gave for exercising differed significantly in terms of their level of importance, Wilks’ Lambda $=.124, F(9,208)=163.99, p<.0001$, partial $\eta^{2}=0.87$. The most important reasons for exercising were to improve physical health and selfworth/concept. Improvements to mood and physical appearance were also rated as important. Preventing illness/injury, socializing to make friends, preparing for sport competitions, and meeting potential romantic partners were less important reasons for exercising (Table 1). The majority of participants ( $n=202$; 93.9\%) reported changes to their physical activity levels since retirement. Responses to the open ended comments totalled nearly 9,500 words. Three main themes were identified: (1) Finding new meanings in exercise, (2) Negotiating exercise independence, and (3) Repositioning exercise in a broader life context.

(1) Finding new meanings in exercise. The first theme addressed the altered purpose and experience of exercise post-retirement. The vast majority of athletes described activity prior to retirement ('training') as goal-directed, externally moderated, time-consuming and tiring. Most of the athletes had been involved in their sport for many years, and many reported feeling 'burnt-out,' and/or experiencing persistent injuries and pains; thus continuing 
1 with high intensity training was not considered a viable or desirable option. Exercise post-

2 retirement was, for most athletes, perceived as fun, varied and flexible. As one 27-year-old gymnast reported: “It's a relief to go to a class for fun, rather than training to compete."

4

Many athletes embraced the opportunity to try new activities that they had previously eschewed due to the potential for injury or compromising their athletic performance. One 26year-old gymnast reported: “I enjoy trying new things...golf, tennis, anything other than gymnastics because as a gymnast I didn't have time, or I didn't want to be sore."

Although exercising for enjoyment and health benefits were viewed as elements of post-retirement physical activity, some athletes expressed an eagerness to retain a competitive nature. For example, a small number of athletes reported making the transition to 'Cross-fit' (a competitive fitness sport, characterised by high intensity intervals, weightlifting, flexibility and power). Others reported competing in new activities, such as running, cycling or weightlifting. However, the search for alternative activities was often described as difficult, and some athletes struggled to find anything that motivated them as their sport had done. "It has been hard to find anything as mentally challenging or as motivating as gymnastics. It has taken me a long time to figure out what I like to do to workout... I don't know that I've found anything that I like as much.” (25-year-old gymnast)

(2) Negotiating exercise independence. The second theme speaks to the challenges associated with exercising independently and accepting personal responsibility for health and well-being. Many former athletes referred to a highly structured and externally regulated exercise programme when at college, thus retirement presented an opportunity to make personal decisions about their exercise activities. Some athletes stated they did not want to exercise as much as they had previously done. As one 25-year-old gymnast wrote: “My whole life I had to work out, up until I was done with gymnastics. Once it was more of a choice, I just didn't feel like being so active." For others, the loss of exercise structure was 
1 described as anxiety provoking and created significant challenges around developing and

2 adhering to an exercise schedule. Athletes reported struggling to intrinsically motivate themselves to exercise without a specific goal or a coach. Further, athletes described missing the collaborative nature of the coach-athlete relationship, and the collegiality of training with their teammates.

"I do not exercise as much as I used to. I have found that without a coach it is harder to work out, push myself, and to try new things. It's now a lot harder to get to the gym and any excuse is a good one. I have accepted that I am now responsible for myself and my health so it's up to me now."(24-year-old swimmer).

(3) Repositioning exercise in a broader life context. The final theme concerned the ways in which athletes negotiated incorporating exercise into their lives post-retirement from sport. Balancing exercise alongside other occupational, academic and social activities was claimed to be challenging, with many athletes frustrated at the limited time they had to exercise. Indeed, many expressed a desire to incorporate more physical activity into their daily and weekly schedules. Thus, athletes made the most of the time they did have for exercise by engaging in high intensity activities such as running. Moreover, athletes expressed concerns about the impact of reduced exercise on their body shape and weight, which was closely tied to their identity and self-worth. One 27-year-old gymnast wrote: “I feel like I am losing part of who I am because I don't look as strong as I used to.” Physical activity took centre stage for many athletes in college, and adapting to a lifestyle where it was no longer the main focus was difficult. One 26-year-old gymnast described: "It is a difficult transition from being so physically active to having to find time to be active. Physical activity was our 'job' in college, now we have to find time outside work to stay fit.” Despite these frustrations, athletes acknowledged a need to prioritise family and career commitments, and to embrace new opportunities in retirement: 
"There are plenty of things to do in adult life. What was once filled with practicing and working out is filled with lots of other things. There are definitely times I miss being an athlete, but the stage of life I'm in now is fun too.”(24-year-old gymnast)

\section{Discussion}

This is the first study to systematically explore the relationship between years since retirement from collegiate sport and athletes' exercise motives and behaviours. In addition, it explored retired athlete's perspectives towards exercise following their retirement from sport.

The findings indicated that exercise behaviours and reasons for exercise did not vary according to years since retirement (2, 3, 4, 5 or 6 years). The athletes reported exercising in accordance with current physical activity guidelines, and enjoyed exercising for fun and health related reasons. The study offers new insights into the difficulties that retired athletes face in exercising independently, and in accepting a new, less intense exercise routine. Retirement from sport results in many changes to an athlete's lifestyle, including their exercise behaviours and routines (Taylor, Ogilvie, \& Lavallee, 2005). Adjusting to these changes has been suggested to become easier over time (Douglas \& Carless, 2009; Lally, 2007); however exercise motivations and behaviours have yet to be explored during this transition process. The findings demonstrated no associations between years since retirement and athlete's exercise behaviour and motives. Although no clear time frames have been consistently identified for the transition period (Park et al., 2013), it is possible that by two years post-retirement, former collegiate athletes have negotiated an initial crisis period, including changes to exercise, and are starting to construct a new identity beyond sport (Kerr \& Dacyshyn, 2000). The transition may also be easier for collegiate athletes to negotiate in comparison to professional athletes because the completion of college presents a clear end point to their athletic career, which can be anticipated and prepared for (Lally, 2007). Indeed, most of the athletes in this study retired having completed their NCAA eligibility, which may 
1 have helped to provide closure on their involvement in sport (Stambulova et al., 2007).

2 Further research should explore exercise attitudes and behaviours among collegiate athletes

3 immediately post-retirement, and draw comparisons with non-athletes in terms of exercise

4 frequency, type and motivation.

5

6

Regardless of how long they had been retired, athletes exercised in accordance with activity guidelines (Haskell et al., 2007), which is largely in line with existing evidence (e.g., Marquet et al., 2013; Sorenson et al., 2015). We note, however, that the present sample is considerably younger than in previous studies. Athletes expressed a preference for high intensity cardiovascular activities as a time efficient means to alleviate body image concerns and to manage negative mood. Although vigorous physical activity confers significant health benefits (Haskell et al., 2007), our findings also suggest that former female athletes may engage in compensatory exercise behaviours as a mechanism for coping with undesired bodily changes (Lavallee \& Robinson, 2007; Stephan et al., 2007; Stirling et al., 2012). Collegiate athletes coming up to retirement may therefore benefit from support and advice on healthy ways to cope with bodily changes on retirement. In addition, the retired athletes expressed frustrations at being unable to exercise as much as they would like (despite meeting physical activity recommendations), which perhaps indicates an elevated and potentially unhealthy threshold for what they believe constitutes sufficient physical activity. Recalibrating beliefs around what is "appropriate” or "enough" in terms of exercise appears to be an important outcome for retired athletes.

Very few of the athletes played any form of sport in retirement, which contrasts with past research (Clowes et al., 2015; Stambulova et al., 2007). The open-ended responses provided insight into some of the reasons for this discrepancy, with many athletes stating that they felt 'burnt out' and relieved at being able to exercise for enjoyment rather than for performance reasons. In addition, many athletes discussed a lack of intrinsic motivation for 
exercise in retirement. Early specialisation in sport is common among collegiate level athletes (Post et al., 2016), but has been associated with increased risks of burnout and injury (Myer et al., 2015). An early focus on stringent, outcome-oriented training regimens may suppress intrinsic motives for exercise among athletes and thus be potentially detrimental to sustainable post-retirement physical activity (Reifsteck et al., 2016; Sorenson et al., 2015). Therefore athletic departments and sport organizations may need to provide athletes who are nearing retirement with support on how to maintain a physically active lifestyle. In addition, psychological skills training may be valuable to ensure athletes are equipped to manage the potentially difficult transition into retirement. For example, fostering and promoting selfcompassion has been suggested as one mechanism to help athletes manage emotionally difficult sport situations (e.g., Ferguson, Kowalski, Mack \& Sabiston, 2015; Reis et al., 2015). Indeed, higher levels of self-compassion have been associated with increased body acceptance, higher levels of intrinsic exercise motivation, and more active coping styles when faced with negative situations (Ferguson et al., 2015; Magnus, Kowalski \& McHugh, 2010). Self-compassion interventions therefore, may be an effective strategy to promote healthier perspectives towards the changes in exercise and body that often occur in retirement. To advance this line of inquiry, further research should track retired athletes’ exercise attitudes and behaviours longitudinally and over multiple time points. Adopting a prospective design will address retirement-in-action and provide insights into how former athletes' exercise behaviours evolve post-sport. Quantitatively, this may be achieved through the monitoring of exercise attitudes and behaviour patterns. In addition, prospective studies could identify predictors of exercise motivation and engagement among retired athletes, thus facilitating targeted intervention and educational efforts. Furthermore, the athletes in this study were only invited to respond to two open-ended questions exploring changes to their exercise, which is likely to have limited the range and type of responses obtained. Therefore, 
1 to build upon the descriptive thematic analysis presented in this study, researchers should also

2 look to adopt more interpretive qualitative methodologies as a means to better understand

3 how athletes make sense of exercise as athletic retirement progresses. Repeat in-depth

4 interviews with retired athletes would encourage rich descriptions of ongoing exercise

5 experiences and give insight into the factors that shape the construction of new and different

6 understandings of the physically active self. Interpretive studies of this kind might also focus

7 on the experiences of those whose exercise behaviours do not change on retirement from

8 sport. It is equally important to understand what motivates a continued commitment to

9 intense and rigid exercise routines and whether or not this is an adaptive process with healthy

10 outcomes. Although our focus was weight-sensitive sports, future studies should explore whether our findings also apply to other retired athlete groups, such as former non-lean sports participants.

\section{Conclusions}

This innovative study significantly advances our understanding of the exercise

behaviours and experiences of retired female athletes. The results indicate that although retired female athletes exercise in line with physical activity guidelines, they still perceive this to be insufficient and this can lead to feelings of frustration. Retired female athletes demonstrated a preference towards high intensity exercise, which may be driven by body image concerns and difficulties in adapting to a lifestyle where physical activity is no longer the main focus. The findings indicate that athletes may require support on retirement to facilitate the transition towards exercising independently, and in accepting a new, less intense exercise schedule. Future research could adopt interpretive qualitative methodologies to obtain further insight into how athletes make sense of exercise as athletic retirement progresses. 
This study was part of a larger investigation funded by the National Collegiate Athletic

2 Association Sport Science Institute. 
Anderson, C.M., Petrie, T.A., \& Neumann, C.S. (2012). Effects of sport pressures on female collegiate athletes: A preliminary longitudinal investigation. Sport, Exercise and Performance Psychology, 1(2), 120-134.

Beals, K.A. (2003). Eating disorder and menstrual dysfunction screening, education and treatment programs. The Physician and Sportsmedicine, 31(7), 33-38.

Braun, V., Clarke, V., \& Weate, P. (2016). Using thematic analysis in sport and exercise research. In B. Smith \& A.C. Sparkes (Eds.) Routeledge Handbook of Qualitative Research in Sport and Exercise (pp. 191-205). London: Routledge.

Clowes, H., Lindsay, P., Fawcett, L., \& Knowles, Z.R. (2015). Experiences of the pre and

Ferguson, L.J., Kowalski, K.C., Mack, D.E., \& Sabiston, C.M. (2015). Self-compassion and eudaimonic well-being during emotionally difficult times in sport. Journal of Happiness Studies, 16, 1263-1280.

Haskell, W.L., Lee, I.M., Pate, R.R., Powell, K.E., Blair, S.N., Franklin, B.A... \& Bauman, A. (2007). Physical activity and public health: updated recommendation for adults from the American College of Sports Medicine and the American Heart Association. Medicine and Science in Sports and Exercise, 39, 1423-1434.

Kerr, G., Berman, E., \& De Souza, M.J. (2006). Disordered eating in women’s gymnastics: Perspectives of athletes, coaches, parents and judges. Journal of Applied Sport Psychology, 18(1), 28-43.

Kerr, G., \& Dacyshyn, A. (2000). The retirement experiences of elite, female gymnasts. Journal of Applied Sport Psychology, 12(2), 115-133. 
1 Lally, P. (2007). Identity and athletic retirement: A prospective study. Psychology of Sport and Exercise, 8(1), 85-99.

Lavallee, D., \& Robinson, H.K. (2007). In pursuit of an identity: A qualitative exploration of retirement from women’s artistic gymnastics. Psychology of Sport and Exercise, 8(1), 119-141.

Magnus, C.M.R., Kowalski, K.C., \& McHugh, T.L.F. (2010). The role of self-compassion in women's self-determined motives to exercise and exercise related outcomes. Self and Identity, 9 (4), 363-382.

Marquet, L.A., Brown, M., Tafflet, M., Nassif, H., Mouraby, R., Bourhaleb, S... \& Desgorces, F.D. (2013). No effect of weight cycling on the post career BMI of weight class elite athletes. BMC Pub Health, 5, 510.

Myer, G.D., Jayanti, N., Difiori, J.P., Faigenbaum, A.D., Kiefer, A.W., Logerstedt, D., \& Micheli, L.J. (2015). Does early sport specialization increase negative outcomes and reduce the opportunity for success in young athletes? Sports Health. Doi: $10.1177 / 1941738115598747$

Park, S., Lavallee, D., \& Tod, D. Athlete’s career transition out of sport: A systematic review. International Review of Sport and Exercise Psychology, 6(1), 22-53.

Post, E.G., Thein-Nissenbaum, J.M., Stiffler, M.R., Brooks, M.A., Bell, D.R., Sanfilippo, J.L...\& McGuine, T.A. (2016). High school sport specialization patterns of current Division I Athletes. Sports Health, Doi:10.1177/1941738116675455

Reifsteck, E.J., Gill, D.L., \& Labban, J.D. (2016). “Athletes” and “exercisers”: Understanding identity, motivation and physical activity participation in former college athletes. Sport, Exercise and Performance Psychology, 5(1), 25-38

Reis, N.A., Kowalski, K.C., Ferguson, L.J., Sabiston, C.M., Sedgwick, W.A., \& Crocker, P.R.E. (2015). Self-compassion and women athletes’ responses to emotionally difficult sport situations: An evaluation of a brief induction. Psychology of Sport and Exercise, 16(3), 18-25. 
1 Smith, J. K., \& Deemer, D. (2000). The problem of criteria in the age of relativism. In N. K. Denzin \& Y. S. Lincoln (Eds.), The Sage handbook of qualitative research (2nd ed., pp. 877-896). London: Sage.

Sorenson, S.C., Romano, R., Azen, S.P., Schroeder, E.T., \& Salem, G.J. (2015). Life span exercise among elite intercollegiate student athletes. Sports Health, 7(1), 80-86.

Stambulova, N., Stephan, Y., \& Jäphag, U. (2007). Athletic retirement: A cross-national comparison of elite French and Swedish athletes. Psychology of Sport and Exercise, 8(1), $101-118$

Stephan, Y., Bilard, J., Ninot, G., \& Delignieres D. (2003a). Repercussions of transition out of elite sport on subjective well-being: A one year study. Journal of Applied Sport Psychology, 15(4), 354-371.

Stephan, Y., Bilard, J., Ninot, G., \& Delignieres, D. (2003b). Bodily transition out of elite sport: A one year study of physical self and global self-esteem among transitional athletes. International Journal of Sport and Exercise Psychology, 1(2), 192-207.

Stephan, Y., Torregrosa, M., \& Sanchez, X. (2007). The body matters: Psychophysical impact of retiring from elite sport. Psychology of Sport and Exercise, 8(1), 73-83.

Stirling, A.E., Cruz, L.C., \& Kerr, G.A. (2012). Influence of retirement on body satisfaction and weight control behaviors: Perceptions of elite rhythmic gymnasts. Journal of Applied Sport Psychology, 24(2), 129-143.

Taylor, J., Ogilvie, B., \& Lavallee, D. (2005). Career transition among elite athletes: Is there life after sports? In J. M. Williams (Ed.), Applied sport psychology: Personal growth to peak performance (5th ed., pp. 595-615). Columbus, OH: McGraw-Hill

Theberge, N. (2007). 'It's not about health, it's about performance': Sport medicine, health and the culture of risk in Canadian sport. In J. Hargreaves \& P. Vertinsky (Eds.), Physical culture, power, and the body (pp176-195). New York: Routledge. 
1 Weiler, R., Aggio, D., Hamer, M., Taylor, T., \& Kumar, B. (2015). Sedentary behaviour

2

3

4

5

6

7

8

9 among elite professional footballers: health and performance implications. BMJ Open Sport and Exercise Medicine, 1(1), e000023.

Witkowski, S., \& Spangenburg, E.E. (2008). Reduced physical activity and the retired athlete:

A dangerous combination. British Journal of Sports Medicine, 42(12), 952-953.

6 Yardley, L. (2014). Demonstrating validity in qualitative psychology. In JA Smith (Ed.),

7 Qualitative Psychology. A practical guide to research methods (p235-252). London, 8 Sage. 
1 Table 1: Exercise behaviours and reasons for exercising among retired female athletes $(n=$ 2 218)

Mean (SD)

\section{Percentage of exercise time spent in:}

Cardiorespiratory/aerobic/endurance activities (e.g., running, $43.64 \%(30.16)^{\mathrm{a}}$ swimming, biking)

Strength or resistance training (e.g., free weights, kettle bells) $20.21 \%(20.85)^{b}$

Core strength activities (e.g., Yoga, Pilates, Pure Barre) $10.37 \%(18.04)^{\mathrm{C}}$

Cross-fit training $9.08 \%(23.91)^{\mathrm{c}}$

Other physical activities $7.85 \%(23.11)^{\mathrm{c}}$

Exercise classes (e.g., spin, Zumba, etc.) $7.42 \%(15.85)^{\mathrm{c}}$

Playing sports

$1.43 \%(8.30)^{\mathrm{d}}$

Reasons for exercise ( $1=$ not at all important, $7=$ extremely important $) \quad$ Mean (SD)

To improve physical health

$6.23(1.05)^{\mathrm{a}}$

To improve self-worth/concept

$5.96(1.24)^{b}$

To improve mood

$5.80(1.40)^{\mathrm{b}, \mathrm{c}, \mathrm{d}}$

To improve physical appearance

$5.74(1.32)^{\mathrm{c}, \mathrm{d}, \mathrm{e}}$

To improve endurance/cardiorespiratory health

$5.70(1.27)^{\mathrm{c}, \mathrm{d}, \mathrm{e}}$

To improve strength/muscularity

$5.59(1.40)^{\mathrm{d}, \mathrm{e}}$

To prevent illness/injury

$5.23(1.58)^{\mathrm{f}}$

Socialising to make friends

To prepare for sport competitions

$2.51(1.84)^{\mathrm{h}}$

To meet potential romantic partners

$1.94(1.59)^{\mathrm{i}}$ 